\title{
José Saramago e a poética da Insubordinação
}

\author{
JEAN PIERRE CHAUVIN ${ }^{I}$
}

\begin{abstract}
"Os documentos também nada dizem acerca do comportamento sexual normal da população. Mas nem por isso os historiadores se resignam a ignorar tudo a esse respeito."
\end{abstract}

(José Mattoso, 1988, p.26).

"Fulano diz que Beltrano disse que de Cicrano ouviu, e com três autoridades dessas se faz uma história."

(José Saramago, 1989, p.39)

“[...] a história continua precisando ser 'escrita', ou seja, apresentada de alguma maneira."

(Jörn Rüsen, 2010, p.11)

0 ERIA oportuno começar este texto com um episódio anedótico, porventura leve e brejeiro, com vistas a abrandar o tom acadêmico e preparar leitores, eventualmente desavisados, para o pouco que segue. Isso porque dissertar sobre um romance de José Saramago envolve riscos: o primeiro deles é soar óbvio, parafrástico ou redundante. O segundo é desdizer o que afirmam as criaturas de papel, devido à pretensão de adivinhar o que ia na mente do escritor, quando compôs e alinhavou a narrativa. Assim sendo, compartilhar esses apontamentos pressupõe a maior benevolência possível de quem o ler. Nisso, tento seguir os conselhos vistos em Retórica a Herênio (que ensinava como dar início a discursos) com vistas a provocar deleite, ensinar e mexer com as paixões do auditório.

Vamos à historieta. Quando Jaime Bertoluci expôs o projeto que realizaria no Instituto de Estudos Avançados (IEA-USP) e me convidou para ajudá-lo a pensar em nomes para um evento (acolhido e apoiado pelo Instituto), enviei prontamente o título que vai neste ensaio. Àquela altura, ele me pareceu objetivo o suficiente; hoje, penso que ele não deixa muito clara a abordagem que pretendia. Talvez ele recebesse outra denominação, por exemplo: "As três insubordinações de Raimundo". Digo isso porque suponho haver algum interesse em refletir sobre a aproximação entre as palavras "poética" e "insubordinação", maiormente ao nos debruçarmos sobre essa obra. A anedota que se vai ler é mais triste do que alegre.

Em 2010, eu lecionava elevada carga de aulas no Colégio da Polícia Militar, perto da Rua Pedro Vicente, e um punhado de disciplinas na Fatec São Caetano do Sul. O dia 18 de junho caiu numa sexta-feira. Era fim de semestre e 
recordo-me de que fui dar as seis aulas da manhã com um sentimento de orfandade. Ela não se restringia ao aspecto intelectual; mas envolvia uma espécie de vínculo estreito com um sujeito que não cheguei a conhecer. Dois dias depois, em meio à enxurrada de notícias sobre o escritor desde a antevéspera, topei com um jornal do Vaticano, em que o articulista lamentava a postura de Saramago contra a Igreja católica e chegava a celebrar a sua morte. Na ocasião, achei o episódio grotesco, mas curioso: parecia que, involuntariamente, a Igreja reeditava a paixão, a morte e a ressurreição de Jesus, José. Não seria preciso lembrar que, em acordo com os evangelhos, Cristo teria morrido numa tarde de sexta-feira e ressuscitado no domingo... Não poderia haver ironia melhor. É como se o escritor português estivesse a zombar da instituição a partir do além-túmulo.

Como se sabe, Saramago escreveu contos, romances, poemas, peças teatrais, diários de viagem e crônicas. Ele também foi tradutor e revisor, o que sugere estarmos diante de um polígrafo, ou seja, um sujeito bem versado em todas as artes que escreveu e sobre as variadas matérias sobre as quais discorreu. Isso nos leva a considerar alguns dentre os principais temas geradores de sua ficção, que transitaram entre praticamente todos os gêneros e modalidades discursivas.

Salvo engano, e sem prejuízo de outros tópicos, creio que poderíamos nos concentrar em alguns deles: a ficcionalização da história (e as discussões decorrentes); o protagonismo dos subalternos; a (melhor) equalização entre mulheres e homens; a contestação do teísmo; o questionamento das formas invariavelmente mesquinhas do poder, quase sempre calcadas na supremacia do capital; a solidariedade, como uma espécie de antídoto (ou gesto de resistência) contra o comportamento utilitarista e egótico, que caracteriza grande parte de suas personagens; o efeito dos afetos, capazes de desconcertar a suposta ordem do mundo-recompensa em que infravivemos.

Esses temas e motivos comparecem, em maior ou menor medida, à grande parte de seus romances. A relativa harmonia entre homens e mulheres evidencia-se no Manual de pintura e caligrafia, no Memorial do convento, no Evangelho segundo Jesus Cristo, na História do cerco de Lisboa, no Ensaio sobre a cegueira; em Todos os nomes... O alargamento do discurso historiográfico marca tanto o Memorial do convento, quanto a História do cerco de Lisboa, com a diferença de que embasa o enredo, no primeiro caso, e funciona como pretexto para outros acontecimentos, no segundo. Quanto aos demais temas, já referidos, perpassam por praticamente todas as obras, em prosa e verso.

Aparentemente, a questão seria mais simples de resolver se a obra de José Saramago se limitasse ao emprego de temas mais, ou menos, recorrentes. Mas, como sabemos, não é bem o que acontece. Isso porque o seu método de composição relaciona-se intimamente com os gêneros em que escreveu e os tópicos sobre os quais os livros versam. Embora o objetivo maior seja discutir um de seus romances, não poderíamos nos furtar àquela novela que recebeu nome de O conto da Ilba Desconhecida: 
Um homem foi bater à porta do rei e disse-lhe, Dá-me um barco. A casa do rei tinha muitas mais portas, mas aquela era a das petições. Como o rei passava todo o tempo sentado à porta dos obséquios (entenda-se, os obséquios que lhe faziam a ele), de cada vez que ouvia alguém a chamar à porta das petições fingia-se desentendido, e só quando o ressoar contínuo da aldraba de bronze se tornava, mais do que notório, escandaloso, tirando o sossego à vizinhança (as pessoas começavam a murmurar, Que rei temos nós, que não atende), é que dava ordem ao primeiro-secretário para ir saber o que queria o impetrante, que não havia maneira de se calar. Então, o primeiro-secretário chamava o segundo-secretário, este chamava o terceiro, que mandava o primeiro-ajudante, que por sua vez mandava o segundo, e assim por aí fora até chegar à mulher da limpeza, a qual, não tendo ninguém em quem mandar, entreabria a porta das petições e perguntava pela frincha, Que é que tu queres. O suplicante dizia ao que vinha, isto é, pedia o que tinha a pedir, depois instalava-se a um canto da porta, à espera de que o requerimento fizesse, de um em um, o caminho ao contrário, até chegar ao rei. Ocupado como sempre estava com os obséquios, o rei demorava a resposta, e já não era pequeno sinal de atenção ao bem-estar e felicidade do seu povo quando resolvia pedir um parecer fundamentado por escrito ao primeiro-secretário, o qual, escusado se ria dizer, passava a encomenda ao segundo-secretário, este ao terceiro, sucessivamente, até chegar outra vez à mulher da limpeza, que despachava sim ou não conforme estivesse de maré. (Saramago, 2009, p.5-9)

As linhas iniciais de $O$ conto da Ilha Desconbecida se relacionam explicitamente ao que será observado sobre o romance História do cerco de Lisboa. Ambas as narrativas envolvem a sublevação de homens, tidos por comuns, frente ao discurso supostamente nobre e elevado da história (no conto, personificada no rei; no romance, centrada nos manuais de história de Portugal). Para isso, mostram-se perseverantes, ainda que quando diminuídos pela forte e vagarosa burocracia instituída, quando mais convém, pelos poderosos.

Particularmente em História do cerco de Lisboa, caberia falar no caráter "metaficcional" da narrativa (Carvalho, 1998; Arnaut, 2002; Gobbi, 2011), que colabora no embaralhamento entre o plano da ficção e da historiografia. Relembro, com Ana Paula Arnaut (2002, p. 306), o “[...] pleno direito que a ficção tem de por em causa a História, duvidando quer dos seus métodos[,] quer das suas opções para conferir maior relevo a uma ou outra figura, a um ou outro evento, assim instaurado, ou pelo menos propondo novos cenários do que poderia ter acontecido". Sob esse aspecto, o escritor poderia ser visto como um sujeito capaz de suspender juízos, especialmente quando coloca incertos princípios e valores em questão.

Antes de prosseguirmos, considere-se o título que este ensaio leva. O primeiro termo ("poética") pressupõe que o autor da História do cerco de Lisboa teria obedecido a certas preceptivas que interferem diretamente nos temas abordados e no modo de composição. Se preferirem, afirmaria mais simplesmente 
que, nestas páginas, a acepção de "poética” se relaciona a uma espécie de estilística composicional saramaguiana - por sinal, examinada por especialistas de maior calibre. Em consonância com a leitura de Márcia Valéria Zamboni Gobbi (2011, p.67-8):

A fidelidade discursiva do romance em relação ao registro historiográfico chega, por vezes, a ser praticamente literal, como neste fragmento em que os árabes respondem à proposta dos portugueses, feita antes do cerco, para que eles se retirassem pacificamente da cidade, portanto, na iminência da luta armada. Diz o texto de Herculano, dando voz ao porta-voz dos árabes: "Fazei o que o poderdes, concluíam eles; nós faremos o que for da divina vontade" [19--, p. 21]. Diz o personagem mouro na História do Cerco de Lisboa: "Não vos demoreis mais tempo, fazei o que puderdes, nós o que for da vontade de Deus" [Saramago, 1989, p. 205].

Fosse por obedecer a determinados preceitos prévios à sua ficção, fosse do ponto de vista estético, há uma recorrência de expedientes, localizados em outras obras do autor, empregados com maestria na História do cerco de Lisboa. Isso talvez explique algum desconforto, quando lemos "poética" e "insubordinação", já que "poética” pressupõe alguma regularidade de temas, ocorrências e estilos no texto, enquanto "insubordinação" leva a pensar justamente no contrário, ou seja, na desobediência à história, a autoridade, às normas de composição, às ditas tendências literárias etc. Talvez seja possível propor uma síntese. Digamos que o narrador do romance se vale de seu domínio da língua, dos meneios da linguagem e da arte de narrar episódios para subverter tanto o texto historiográfico, quanto para dilatar o alcance do discurso literário.

A esse respeito, Eduardo Calbucci (1999, p.66) ressalta que: “As duas narrativas, a de Raimundo e a de Saramago, misturam-se, criando um discurso polifônico, de vozes diferentes que pouco a pouco chegam aos limites da criação ficcional, em que o passado é recuperado pelo presente, mas sob a nova perspectiva que foi aberta pelo revisor". Por sua vez, Ana Paula Arnaut (2002, p.304-5) salienta que "[...] o historiador pode ingenuamente acreditar estar a contar a verdade. No entanto, essa será sempre uma verdade relativa pois, ad exemplum no caso em que o número de fontes se revele insuficiente", a resvalar na "pretensão de totalidade" - como José Mattoso $(1988$, p.17) alertava em $A$ escrita da história.

Seria razoável abordar esse romance a partir do que Vera Bastazin (2006, p.21) observou sobre $O$ evangelho segundo Jesus Cristo, publicado em 1991: "Tempo e história constroem a trama ficcional no romance, colocando em evidência que qualquer limite entre o real e o imaginário é apenas mais um artifício do texto literário”. Recorro novamente a Márcia Valéria Zamboni Gobbi (2011, p.15), que salienta um aspecto essencial na literatura contemporânea, a confrontar o "esgarçamento de sentido", comum ao nosso tempo: "Uma de suas formas de combate é justamente ancorar-se na História, na tentativa de perceber 
a dimensão e o alcance de uma experiência singular inserida na continuidade, nas transformações e nas rupturas - na dinâmica histórica, enfim -, talvez convencida de que a circulação generalizada da percepção histórica constitui não só a especificidade, mas também a identidade do nosso tempo como instala, paralelamente, um desafio, pois a ninguém se permite ficar fora da História” (ibidem).

Feitas essas ressalvas e acomodadas eventuais diferenças entre a dicção ficcional e a pretensão historiográfica à verdade, creio que o segundo termo ("insubordinação") poderia sugerir que José Saramago atribuíra a Raimundo Silva a capacidade de questionar a autoridade dos editores, a responsabilidade por esticar o conceito de fato histórico e problematizar as posições, por vezes assimétricas, entre homens e mulheres. Os questionamentos do revisor situam-se em capítulos facilmente localizáveis no volume e dizem respeito a três aspectos, mais ou menos distintos, de sua vida. No âmbito profissional, a autoridade do chefe é colocada em xeque; no plano intelectual, a subversão da história de Portugal concentra-se no acréscimo de um advérbio de negação; na esfera pessoal, a negociação com Maria Sara só acontece após esses lances, que parecem “preparar” Raimundo para o passo maior, para além da vida rotineira e do ofício que ocupa a maior parte do seu tempo.

Esses e outros eventos são dispostos linearmente, no romance. O que os episódios guardam em comum? A impaciência do revisor, perante acordos unilaterais impingidos pelos editores; o questionamento da palavra oficial; o temor frente à intimidade com a mulher. Eles nos autorizam supor que a pequena história do revisor acontece no instante em que o éthos de Raimundo Silva é colocado à prova e permite ultrapassar os limites de sua existência apequenada. Decorre daí uma possível chave de leitura: para uma mesma poética, no romance, há pelo menos três modos de insubordinação concentradas na figura do protagonista, no trabalho do revisor e na vida íntima de Raimundo. Instância narrativa multifacetada, a enunciação poderia ser examinada sob três perspectivas. Nesse sentido, a subversão da história tradicional, a rebeldia profissional e o enfrentamento da inibição pessoal são pequenas revoluções nascidas de um homem que ganha força e forja o caráter porque as articula. As três insubordinações de Raimundo sugerem que a mudança postural da personagem corresponde, necessariamente, à infração editorial (daí, o embate com o empregador); e ao difícil desnudamento físico e ético, perante Sara Maria.

Para transitar do âmbito descritivo para o analítico, conviria examinar alguns excertos do romance, com vistas a calçar os pressupostos anunciados. Após a leitura e análise deles, talvez possamos arriscar algumas hipóteses interpretativas. Principiemos:

Em Raimundo Silva, os motivos que em momento algum da sua vida haviam sido de rancorosa frustração, são hoje, uns, meramente estéticos, por não lhe soar bem a vizinhança dos dois gerúndios [Raimundo Benvindo], e os outros, por assim dizer, éticos e ontológicos, porque, segundo a sua 
maneira desenganada de entender, só uma ironia muito negra pretenderia fazer crer que alguém é realmente bem-vindo a este mundo, o que não contradiz a evidência de alguns se acharem bem instalados nele. (Saramago, 2003, p.28)

A passagem escande os incômodos do protagonista com relação ao seu nome do meio (Benvindo). Como adivinha o narrador, um dos fatores é estético e passa pela sonoridade redundante de Raimundo e Benvindo. O segundo motivo começa com o aspecto semântico e envolve o conceito subjacente a quem seja nomeado como bem-vindo a um mundo que lhe parece inóspito. Não se trata de pormenor digressivo ou acidente literário. A discussão em torno do nome da personagem também se relaciona à sua identidade, ou seja, a maneira como é classificado (e como se percebe) entre bilhões da sua espécie, particularizado dentre outros revisores chamados Raimundo e atrelado ao humilde ofício de revisor de textos. "Raimundo", dissera Drummond, pode rimar com "mundo", mas não traduz nem implica solução. No romance, o protagonista passa por um visível processo de mudança. O circuito se fecha: parece lógico que o questionamento sobre si mesmo envolva refletir sobre o som e o caráter irônico embutido em seu nome.

Do exame centrado no protagonista, passemos a discutir uma ação relacionada a outras figuras do romance:

Ia a manhã em meio quando o telefone tocou. Era da editora, queriam saber notícias sobre o andamento da revisão, quem começou por falar foi a Mônica da Produção, que tem, como todos os que trabalham nesse sector, o hábito da menção majestática, assim, Senhor Silva, disse, a Produção pergunta, parece que estamos a ouvir, Sua Alteza Real quer saber, e repete como os arautos repetiam, a Produção pergunta pelas provas, se falta muito para entrega-las, mas ela, a Mónica, ainda não percebeu, depois de tanto tempo de vida em parte comum, que Raimundo Silva detesta que lhe chamem Silva sem mais nada, não que lhe o aborreça a vulgaridade do nome, que anda pela dos Santos e Sousas, mas porque lhe faz falta o Raimundo, por isso respondeu, seco, ferindo injustamente a pessoa delicada que Mónica é, Diga lá que amanhã está pronto o trabalho, Eu digo, Senhor Silva, eu digo, e mais não acrescentou porque, o telefone foi tomado bruscamente por outra pessoa, Fala Costa, Aqui Raimundo Silva, pôde o revisor responder, Já sei, é que as provas preciso delas ainda hoje [...] Para este tipo de livro, assunto, número de páginas, o tempo de revisão está dentro da média, Não me venha com médias, quero o trabalho acabado, a voz do Costa subira, sinal de que deveria estar por perto um chefe, um diretor, talvez o próprio patrão. (Saramago, 2003, p.32-3)

O segundo excerto envolve o tenso diálogo entre Mónica e, depois, Costa com o revisor. Aqui, a gradação ascendente dos postos hierárquicos é reforçada pela interrupção da rotina de Raimundo, evidenciada pela disposição dos períodos frasais no parágrafo. Mónica estava próxima de Costa que, a seu turno, 
estava a meia distância do patrão. A linguagem de um e outro confirma o desconforto da assimetria. Mónica, funcionária menos graduada da editora, gasta mais palavras ao se dirigir respeitosa e cerimoniosamente ao "Senhor Silva". Fenômeno contrário se observa na fala ríspida e econômica de Costa, situado num entre-lugar: nem funcionário sem poderes, nem patrão plenipotenciário.

$\mathrm{O}$ extrato seguinte revela o conflito que se estabelece entre o sujeito e as ideias que vão nele:

As palavras que o Dr. Jekill acabou de dizer tentam opor-se a outras que não chegámos a ouvir, essas disse-as Mr. Hyde, não seria preciso mencionar esses dois nomes para percebermos que neste prédio velho do bairro do Castelo assistimos a mais uma luta entre o campeão angélico e o campeão demoníaco, esses dois de que estão compostas e em que se dividem as criaturas, referimo-nos às humanas, sem exclusão dos revisores. Mas, esta batalha, desgraçadamente, vai ganhá-la Mr. Hyde, percebe-se pela maneira como Raimundo Silva está a sorrir neste momento, com uma expressão que não esperaríamos dele, de pura malignidade, desapareceram-lhe do rosto todos os traços do Dr. Jekill, é evidente que acabou de tomar uma decisão, e que má ela foi, com a mão firme segura a esferográfica e acrescenta uma palavra à página, uma palavra que o historiador não escreveu, que em nome da verdade histórica não poderia ter escrito nunca, a palavra Não, agora o que o livro está a dizer é que os cruzados Não auxiliarão os portugueses a conquistar Lisboa, assim está escrito e portanto passou a ser verdade. (Saramago, 2003, p.44)

Na terceira amostra, o narrador alude à célebre personagem de Robert Louis Stevenson, em romance publicado em 1886, com 103 anos de antecedência. Uma violenta dicotomia assaltara o espírito do revisor, diante de uma narração historiográfica que lhe pareceu inverossímil. A evocação da criatura meio homem/meio monstro, criada pelo romancista escocês, é análoga à indecisão do revisor (entre a assertiva e a negativa) e pode sugerir que o acréscimo do não seria um gesto paradoxal. A explicação parece voltar-se para os artifícios linguísticos empregados pelo narrador saramaguiano, que desafiam a própria concepção de tempo e registro historiográfico.

José Francisco Rodrigues de Carvalho (1998, p.83) assinalou que: “Em Saramago ocorre, possibilitada pela ficção e por novas concepções de História e narrar, uma mistura dos tempos que possibilitará também a revisão histórica a partir do questionamento da visão linear e estratificada que serve de base, por exemplo, a Herculano. A interpenetração dos tempos, entretanto, não se dá de súbito[,] mas constrói-se paulatinamente".

$\mathrm{Na}$ leitura da História do cerco de Lisboa devemos atentar para o papel desempenhado pelo narrador, que "por meio de suas constantes intervenções de caráter metalinguístico ou metaficcional, comporta-se como um ser acima do universo ficcional criado ao estabelecer, por exemplo, jogos temporais que evidenciam o caráter manipulador de seus domínios sobre a narrativa" (Gobbi, 
2011, p.77). Em termos mais restritos, qual seria a implicação embutida no pequeno grande ato de se acrescentar um elemento (no caso, o advérbio "não") cuja presença subtrai? A intervenção do revisor indica que os questionamentos de Raimundo Silva ultrapassaram o âmbito pessoal e contagiaram outras esferas, talvez menores que antes, de sua vida. Maria Alzira Seixo (1999, p.75) constatou que:

A História é, portanto, o Livro; e daí que todo o livro tenha de se remeter à História. É certo que este é, nos romances de Saramago, aquele onde o discurso da História mais lugar ocupa, tendo, no entanto, uma ocupação diegética reduzidíssima, quase inexistente, tornada símbolo ou pretexto indicial de formulação da intriga. Isto é: o que efetivamente acontece, no universo ficcional, é o namoro de Raimundo e Maria Sara, os dois funcionários da editora que publica o livro História do Cerco de Lisboa; se isso acontece, porém, é porque Raimundo praticou um erro na revisão das provas e, desse erro, vai surgir a presença da doutora Maria Sara na editora e a sua (dele) outra escrita no mesmo sucesso. Caminha-se, assim, da História como hesitação de discursos na aproximação ideal com o Livro para a História do próprio presente.

O diálogo com o célebre e inusitado enredo de Stevenson reforça não só dicotomia moral enfrentada por Raimundo Silva; sinaliza para a dificuldade em distinguir entre a potência do texto ficcional e a intenção do discurso historiográfico. Acompanho Márcia Gobbi (2011, p.27), para quem: "Parece inevitável, então, que tomemos as duas instâncias, História e ficção, como textos, uma vez que só temos da História, mesmo a contemporânea, a sua versão textualizada, o discurso sobre o acontecimento ou, na formulação mais extrema de Hayden White (1992), os "restos textualizados da História"”.

O próximo excerto traz o primeiro contato entre o "revisor" Raimundo Silva e a "doutora" Maria Sara, ao telefone:

[...] o próprio rosto de Raimundo Silva se crispa enquanto do outro lado a doutora Maria Sara, serena, num gesto evidentemente gracioso, atira para trás, com um movimento de cabeça, o cabelo do lado esquerdo para poder encostar o auscultador ao ouvido, e diz finalmente, Não fomos apresentados no outro dia, mas apresento-me agora a mim mesma, o meu nome é Maria Sara, o seu ia a dizer, Já o conheço, mas Raimundo Silva, arrastado pelo hábito, disse o seu nome, mas disse-o o completo, declarou-se Benvindo, e quase morreu de ridículo ali mesmo. A doutora Maria Sara, porém, apesar de não ter enunciado da sua pessoa mais do que esse pouco, não fez reparo na confissão, tratou-o por senhor Raimundo Silva, sem poder adivinhar quanto bálsamo estava derramando na macerada susceptibilidade do revisor, Gostaria de falar consigo sobre o modo de organizarmos o nosso trabalho, estou a ter encontros com todos os revisores, interessa-me saber o que pensam, sim, encontros pessoais, não há outra maneira, amanhã ao meio-dia, se lhe convier, de acordo, fico à sua espera, até amanhã. O telefo- 
ne já fora desligado, e Raimundo Silva ainda não recuperara por completo a serenidade, agora a casa está cheia de silêncio, apenas se adivinha uma pulsação inaudível, tanto pode ser o arfar da cidade como o mover do rio, ou simplesmente o coração do revisor. (Saramago, 2003, p.91-2)

Temos um novo diálogo ao telefone. Esse caso, porém, é outro. Os turnos da fala são capitaneados por Maria Sara - mais senhora de si do que Raimundo Silva respondia por ele. Os sintomas do afeto que Raimundo alimenta pela mulher refletem-se na enunciação lacunar do narrador. Adivinhamos as perguntas e réplicas de Raimundo, mas não porque as tenhamos lido. Ao omitir a voz do sujeito e privilegiar o discurso da mulher, o revisor nos induz a supor que a insubordinação de Raimundo se defrontara com um limite intangível, para além das métricas relacionadas ao ofício de revisor. A disputa pela razão, que também é uma forma de reafirmar poder, cede terreno à desordem dos afetos, que converte apaixonados em seres apassivados, mais dóceis e menos eloquentes.

Aqui interessam os pequenos gestos e as grandes hesitações de Raimundo, enquanto balbucia palavra e outra ao telefone, em duro diálogo com Maria Sara. Todos os aspectos de sua vida parecem estar submetidos a um novo modo de conceber e sentir. A essa altura, a ordem dos afetos ainda não atingiu o flanco deixado em aberto pelo revisor; mas o diálogo com a "doutora", sua superiora hierárquica, dali em diante, antecipa os gestos duros, a palavra presa, os modos apequenados do homem. Raimundo poderia ser metáfora da cidade, com suas cores do dia, e pulsações dos sujeitos que protagonizam a pequena grande história do cotidiano. A história particular de Raimundo Silva parece imiscuir-se, embaralhar-se à História de Portugal, país em que ele, deslocado, habita.

A revolução das coisas, no âmbito pessoal, associa-se à dilatação dos prazos para consecução do trabalho revisional, perante o chefe; mas também dialoga com o desafio ao senso comum, lançado por Raimundo, face à reprodução de meias-verdades em determinados livros de história. Essas dicotomias também dizem respeito aos limites da narrativa que preenche as páginas de um romance subintitulado ensaio. Para aqueles que tanto se esforçam na discussão de gêneros, torna-se complexo definir (e, portanto, delimitar) o romance. Maria Alzira Seixo notou, com perspicácia, que:

É certo que o erro [atribuído a Raimundo] tem também uma função gnoseológica: o Livro dos Conselhos que Saramago inventa propõe a correcção para o alcance da verdade; mas, à parte a confusão casuística que lavra entre essas dúbias noções de erro e de emenda, ou da emenda como erro, ou do erro como forma dúbia de atingir a verdade, também a epígrafe que desse livro se extrai termina com a incitação "entretanto, não te resignes", que aponta justamente para a adequação da temporalidade ao tempo, e para o investimento do projecto no concreto. (Seixo, 1999, p.77)

A essa altura, reitere-se que é redutor classificar a História do cerco de Lisboa como exemplar ora mais, ora menos romanesco. Tampouco será produtivo 
rotulá-lo com a etiqueta de "romance histórico", supondo conferir ao romance maior ou menor valor e estatura - a depender do repertório, do grau de criticidade e da concepção sociopolítica (mais ou menos exclusiva) de seu leitorado. Talvez seja mais oportuno abordar a obra como materialização discursiva de diferentes estratos do tempo - nos termos de Koselleck (2014), que ocorrem simultaneamente ao acionamento de acordes, ora harmônicos, ora dissonantes, produzidos pelas vozes que brotam dessas surpreendentes criaturas de papel.

\section{Referências}

ARNAUT, A. P. Post-modernismo no romance português contemporâneo: fios de Ariadne, máscara de Proteu. Coimbra: Almedina, 2002.

BASTAZIN, V. Mito e poética na literatura contemporânea: um estudo sobre José Saramago. Cotia: Ateliê, 2006.

CALBUCCI, E. Saramago: um roteiro para os romances. Cotia: Ateliê, 1999.

CARVALHO, J. F. R. de. Herculano, Saramago e a História do cerco de Lisboa. In: LOPONDO, L. (Org.) Saramago segundo terceiros. São Paulo: Humanitas, 1998. p.77110.

GOBBI, M. V. Z. A Ficcionalização da história: mito e paródia na narrativa portuguesa contemporânea. São Paulo: Editora Unesp, 2011.

KOSELLECK, R. Estratos do tempo: estudos sobre história. Trad. Markus Hediger. Rio de Janeiro: Contraponto, 2014.

MATTOSO, J. A escrita da história - teoria e métodos. Lisboa: Editorial Estampa, 1988.

RÜSEN, J. História viva - Teoria da história III: formas e funções do conhecimento histórico. Trad. Estevão de Rezende Martins. Brasília: Editora da UnB, 2010.

SARAMAGO, J. História do cerco de Lisboa. Rio de Janeiro: O Globo; São Paulo: Folha de S.Paulo, 2003 [1989].

. O conto da Ilba Desconhecida. São Paulo: Companhia das Letras, 2009.

SEIXO, M. A. Lugares da ficção em José Saramago. Lisboa: INCM, 1999.

RESUMO - No ensaio, aborda-se a caracterização das personagens e se examinam por que, quando e como acontecem os gestos de insubordinação por parte do revisor Raimundo Benvindo Silva: sujeito simples alçado ao protagonismo de uma história sobre a História. Sendo uma interpretação de caráter interdisciplinar, no artigo discutem-se as fronteiras entre o discurso ficcional e o historiográfico, a partir dos pressupostos da Teoria da História e da Crítica Literária.

PALAVRAS-CHAVE: Literatura, História, José Saramago.

ABSTRACT - In this essay, we analyze how characters are depicted and examine why, when and how the gestures of insubordination of reviser Raimundo Benvindo Silva occur. $\mathrm{He}$ is a simple man raised as protagonist of a story about History. Converging into an inter- 
disciplinary interpretation, this article discusses boundaries between fictional and historiographic discourses based on assumptions of History Theory and Literary Criticism. KEYWORDS: Literature, History, José Saramago.

Jean Pierre Chauvin é doutor em Teoria Literária e Literatura Comparada pela Faculdade de Filosofia, Letras e Ciências Humanas da USP. Professor responsável pela disciplina de graduação A prosa de José Saramago na Escola de Comunicações e Artes da USP. Docente credenciado no Programa de Pós-Graduação Estudos Comparados de Literaturas de Língua Portuguesa, vinculado ao Departamento de Letras Clássicas e Vernáculas da FFLCH-USP. @ - tupiano@usp.br /

http://orcid.org/0000-0001-9514-109X

Recebido em 4.12.2019 e aceito em 14.2.2020.

I Faculdade de Filosofia, Letras e Ciências Humanas, Universidade de São Paulo, São Paulo, Brasil. 
